IRA-International Journal of Education \&

Multidisciplinary Studies

ISSN 2455-2526; Vol.17, Issue 01 (Q1, 2021)

Pg. no. 27-34.

IRA Academico Research

\title{
A Cognitive Study of the Multimodal Metaphors in National Publicity Documentaries China Enters a New Era: A Case Study of National Image
}

\section{Ma Chao}

School of Foreign language, Zhejiang University of Finance and Economics, Hangzhou, China.

Type of Work: Peer Reviewed.

DOI: $10.21013 /$ jems.v17.n1.p4

DOI URL: https://dx.doi.org/10.21013/jems.v17.n1.p4

\section{How to cite this paper:}

Chao, M. (2021). A Cognitive Study of the Multimodal Metaphors in National Publicity Documentaries China Enters a New Era: A Case Study of National Image. IRA-International Journal of Education \& Multidisciplinary Studies (ISSN 2455-2526), 17(1), 27-34. DOI: https://dx.doi.org/10.21013/jems.v17.n1.p4

(C) IRA Academico Research.

(cc) Br-No This work is licensed under a Creative Commons Attribution-NonCommercial 4.0 International License subject to a proper citation to the publication source of the work.

Disclaimer: The scholarly papers as reviewed and published by IRA Academico Research are the views and opinions of their respective authors and are not the views or opinions of IRA Academico Research. IRA Academico Research disclaims of any harm or loss caused due to the published content to any party.

IRA Academico Research is an institutional publisher member of Publishers International Linking Association Inc. (PILA-CrossRef), USA. IRA Academico Research is an institutional signatory to the Budapest Open Access Initiative. Hungary advocating the open-access of scientific and scholarly knowledge. IRA Academico Research is a registered content provider under Open Access Initiative Protocol for Metadata Harvesting (OAl-PMH).

The journal is indexed \& included in WorldCat Discovery Service (USA), CrossRef Metadata Search (USA), WorldCat (USA), OCLC (USA), Open J-Gate (India), EZB (Germany) Scilit (Switzerland), Airiti (China), Bielefeld Academic Search Engine (BASE) of Bielefeld University, Germany, PKP Index of Simon Fraser University, Canada. 


\section{ABSTRACT}

Recent years have witnessed great interests on multimodal communication due to the rapid development of information technology. Multimodal texts of different genres have sparked great interest of researchers in linguistic study. Based on the cognitive mechanism of multimodal metaphor, this study attempts to figure out the types of metaphor in National Image Publicity Documentary China enters a new era, meaning construction of multimodal metaphors, and what kinds of national image have been constructed by multimodal metaphor.

Keywords: National Image, Multimodal Metaphors, China Enters a New Era

\section{Introduction}

Researches on metaphor can be traced back to ancient Greece. At that time, metaphor was studied within the frame of the discipline labeled as rhetoric. In rhetoric, metaphor was used to persuade others of a particular view. However, it is in the work by Lakoff and Johnson, published in 1980 and entitled Metaphor we live by, that we can notice a big revolution in this research area. Lakoff \& Johnson (1980) argues that metaphor is not only a rhetoric device, but also a way of thinking and acting; metaphor is a matter of thought and action, and language is just an external manifestation of metaphor (Lakoff \& Johnson, 1980). From this study, the understanding about the world starts to be related to the concept of metaphor, since a great number of basic concepts, as time, quantity, state, action, etc.; besides emotional concepts as anger and love, are metaphorically understood (Sperandio, 2020). This makes clear the importance of metaphor role in the understanding of the world, of the culture and even of ourselves. In recent years, with the development of cognitive linguistics, more opportunities have been created for the study of multimodal discourse. And as typical multimodal discourse, National Image Publicity Documentary (NIPD) has also attracted much attention.

National image is the representative of country's soft power, and also is the one of the manifestations of a country's comprehensive strength. Thanks to reform and opening up, great changes have taken place in China's economy, technology and the quality of people's living. However, some countries' impression on China remains in those stereotypes, full of stubborn prejudice. Wang \& Xin (2019) analyzes the news reports from some popular media and concludes that China's images are "enemy and opponent of US" and "the supporting player seizing the leading part of US" which is on the contrary to China's self-awareness. Thus, to promote China effectively to the world, sustainable communication strategy is necessary. Since 2008, Chinese Government has officially launched the filming of the National Image Publicity Documentary (NIPD) to show the national image to foreign audience through test, sound and images. However, it still remains unknown whether the image can affect the foreign audience's perception of China's national image in a positive way. Thus, the present study, based on the cognitive mechanism of multimodal metaphor, tries to deconstruct the China's national images in the publicity documentary: China Enters a New Era.

\section{Studies on Multimodal Metaphor}

Since 1990s, a group of scholars, such as Forceville (2009), Ning (2009) an EL Refaie (2003) etc., taking reference from other disciplines, have extended the studies of conceptual metaphor to interdisciplinary studies. Research from multimodal approach is a fusion of cognitive linguistics and 
multimodal discourse, which indicates that the study of conceptual metaphor has entered into a new stage.

Based on a corpus of 29,925 words of corporate mission statements, Koller (2009) explores the multimodal metaphors in corporate branding messages. In this study, illustration, logo and layout in visual and verbal mode are discussed. Within the cognitive linguistic paradigm, Yu (2009) intends to analyze the nonverbal and multimodal manifestations of metaphors and metonymies in an educational commercial screened on China Central Television (CCTV). Specifically speaking, it shows how two major conceptual metaphor, LIFE IS A JOURNEY and LIFE IS A STAGE, are manifested in dynamic visual and aural, as well as verbal, discourse. At same year, Rohdin (2009) presents the discussion of multimodal metaphor in classical film theory from the 1920s to the 1950s. Throughout this study questions of identification and interpretation of film metaphor are discussed, and it is claimed that formal criteria are not sufficient to adequately describe the rich variety of multimodal metaphors. With reference to the categorization of visual metaphor proposed by Charles Forceville, Hou and Zhao (2010) firstly makes a tentative categorization of the multimodal metaphors. And then it makes elaborations concerning composition as well as interpretation of visual metaphors. It is found that Visual metaphor is prone to altering consumers, cognitive context, hence enhancing the potential impact. Jiang and Wang (2013) analyze the usage of speech, gesture mono-metaphor and speech-gesture multimodal metaphor in the impromptu speech and question-answering sessions of six high-level foreign language learners. On the basis of reclassification and redefinition of modality categorization and definition of multimodal metaphor, Zhao (2013) presents a model of conceptual integration for the construction of multimodal metaphor. In her papers, the progress of integration is elaborated with a case study of political pictorial discourses.

Review of previous studies on multimodal metaphor finds that previous researches on multimodal metaphor mainly focus on advertisement especially print advertisement, commercial advertisement, picture books and political cartoons while the NIIPD of China attracts comparatively less attention.

\section{Methodology}

\subsection{Research Corpus-China's NIPD}

China enters a new era was released on the People's Daily app on October 21, 2017. Lasting about 3 minutes, it centers on 7 characters of different age groups, industries, regions and nationalities, and shapes the changes of China entering a new era by constructing the "Chinese dream" and daily life of each character. Thus, the theme of this documentary is concerned with new era and new changes.

\subsection{Research Objective and Method}

This study attempts to figure out the types of metaphor in NIPD China enters a new era, meaning construction of multimodal metaphors, and What kinds of national image have been constructed by multimodal metaphor. To deal with the above issues, this study raises the following two research questions:

1. What are the types of multimodal metaphors in NIPD China?

2. What kinds of national image have been constructed by multimodal metaphor in the NIPD of China?

There are two research methods employed in this study: literature analysis method and qualitative 
method. First of all, we can get a comprehensive and clear recognition of the current studies on multimodal metaphor by referring to related researches. Through analysis, research findings and gaps can be concluded and the research content of this study can be clearer. Then, through qualitative method, we can classify the types of multimodal metaphors in NIPD China by adopting Forceville's standards on identification of multimodal metaphor. At the same time, the process of meaning construction and construction of national image can be illustrated.

\section{Types of Multimodal Metaphors \& National Image}

This section explores the main multimodal metaphor in China Enters a New Era, such as journey metaphor, emotional metaphor. Combined with the multi-modal characteristics of NIPDs, the following modes are mainly involved in the analysis of this paper: verbal (voice-over and subtitle), visual (static or dynamic images) and aural (background music).

\subsection{Journey Metaphor}

Journey metaphor is an event structure metaphor, which is based on path schema. The path schema contains traveler, starting point, path, end point, direction, and some other factors such as obstacles, landmarks, ways, and traveling companions. Factors such as destination, path, obstacle, destination and failure to reach the destination can metaphorically represent the event goal, the method to achieve the goal, the problem, the success and failure, providing the basic cognitive structure for journey metaphor. Lakoff (1993) reformulated the journey metaphor as "purposeful activity is travelling along a path towards a destination." Charteris-Black incorporated this into a political conceptual metaphor "purposeful social activity is travelling along a path towards a destination."

DEVELOPMENT IS A JOURNEY is a metaphor in the documentary China Enters a New Era, based on the "source-path-goal" schema. This metaphor creates mappings from the source main of journey to the target domain of development as follows:

Table: The Mapping from the "Journey" to the "Development"

\begin{tabular}{|l|l|l|}
\hline \multicolumn{2}{|c|}{ Development is a Journey } \\
\hline & Source Domain & Target Domain \\
\hline a & Journey & Development \\
\hline b & Traveler & China \\
\hline c & Starting Point & Beginning of China's Development \\
\hline d & Path of Journey & Road of China's Development \\
\hline e & Obstacles of Journey & Difficulties in China's Development \\
\hline f & Destination & Goal \\
\hline
\end{tabular}

In the film China Enters a New Era, the traveler is China. She is a confidence and responsible country with profound history and cultural elements. For her, in this journey, the beginning is the reform and opening up. Forty years before, China opened the window to the outside. This historic event has greatly promoted the development of social productive forces and the rise of overall national strength, propelling China into the fast track of development. The path is the socialist road with Chinese characteristics, in view of the basic conditions of China. Forty years of opening, China is able to bravely face and step forward the path of her own choosing. The metaphorical word "path" appears in the form of Chinese subtitles and English commentaries, as well as the dynamic images in terms of 
flying planes and running trains in Figures 1-4, which jointly activates the "path" scene in the journey metaphor. After taking the path, China can be built into a prosperous, strong, democratic, culturally advanced, harmonious and beautiful great modern socialist country like the wishes in the end of film that China will be more beautiful, more prosperous and more wonderful. Forever, the path is not easy and smooth, in the verbal mode "Is tradition a burden, or kind of driving force for development?" Tradition maybe a burden or an obstacle. Finally, in the end of the documentary, "China on the Way" indicates that China is still in the process of development and Chinese are full of expectations for future development.
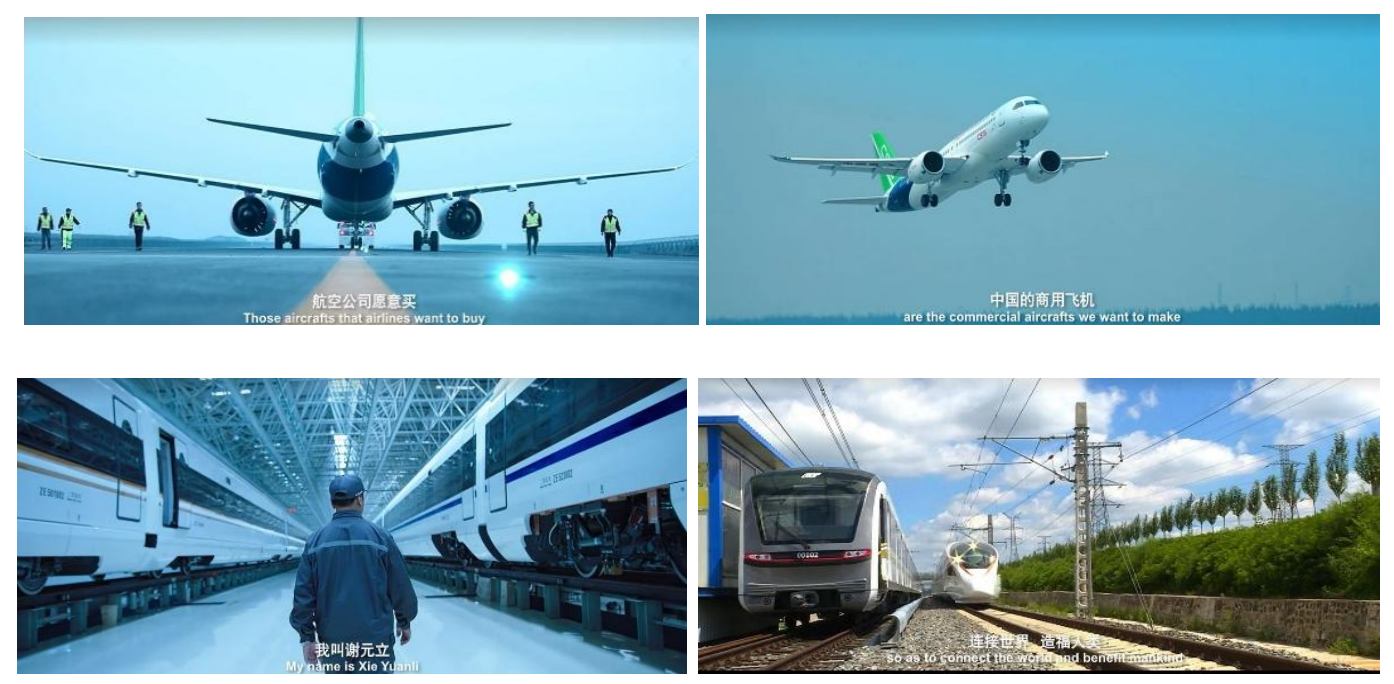

Figure 1-4 Plane \& Train in China Enters a New Era

\subsection{Emotional Metaphor}

The study of emotional metaphor originated from Lakoff \& Johnson(1980). Human emotions are rich and abstract, and are usually materialized and conceptualized. Based on the means of expression of human emotions, emotional metaphors can be divided into following categories: location emotional metaphors, color emotional metaphors, and natural phenomenon metaphors. The following sections will explain color emotional metaphors, and natural phenomenon metaphors respectively in the documentary China Enters a New Era.

Color is an important way to look at the world. Although the expressions of color words are different in human languages, they all follow a common structural order: black, white, red, yellow, green, blue, brown, purple, pink, orange and gray. Color is often used to construct emotional metaphors based on human experience and culture. The meaning of metaphor is closely related to the past experience and cultural background of the reader. Because of the differences in history, culture and living habits, different nationalities have different comprehension of emotional metaphors for colors. There are many colors in the video China Enters a New Era, for example Ruby Red, Fresh Green, Champagne Golden. As seen in the Figures 1-4, they are red door, golden spark, green bamboos, which unfold the happy lives of Chinese people and the harmonious and peaceful China. 

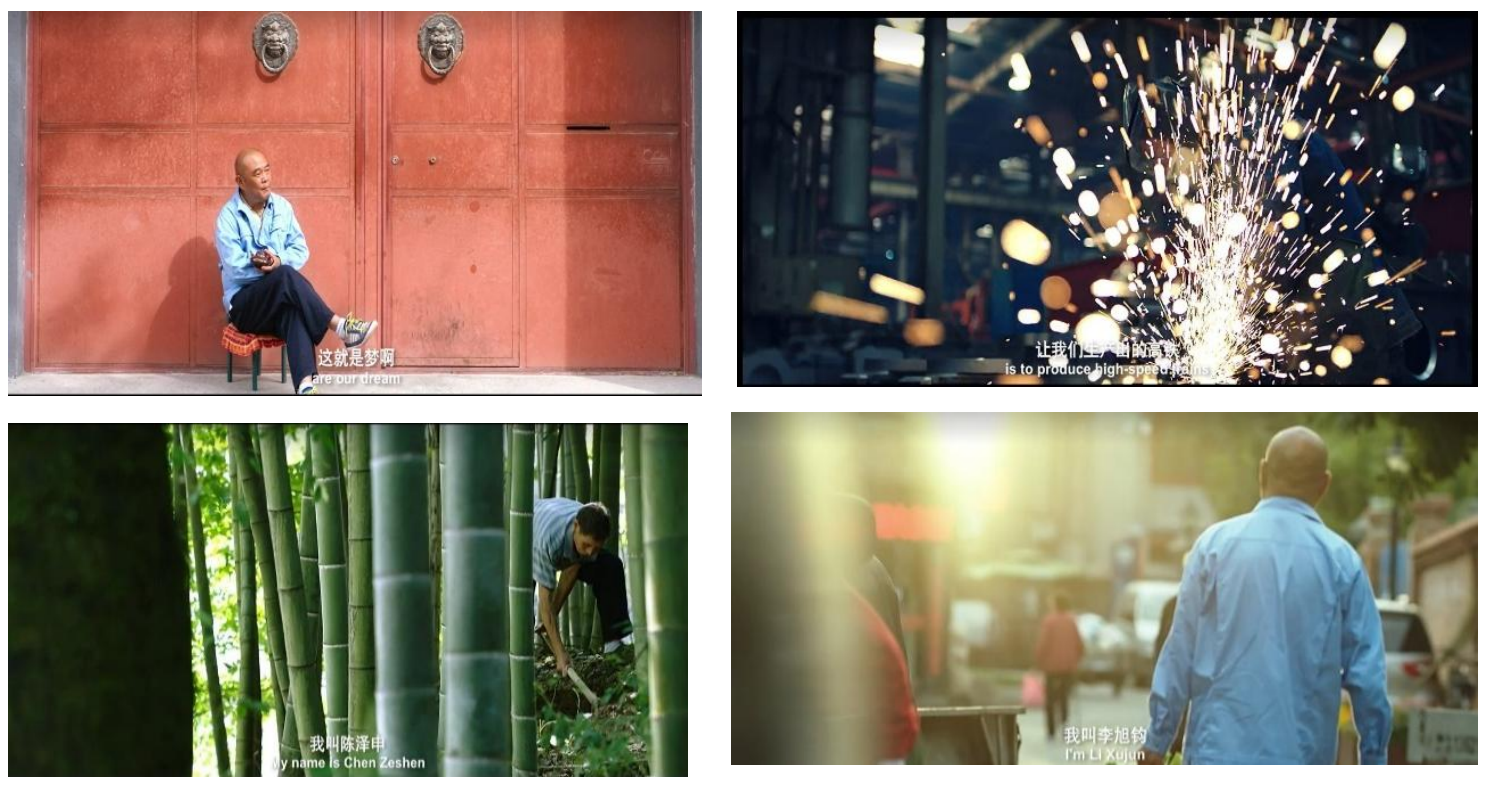

Figure 5-8 Colors in China Enters a New Era

Nature can be felt directly by human beings, where many poets and artists go for inspiration. Many natural phenomena are often used to express emotions, like wind, rain, snow, thunder, lightning, metal, wood, water, fire, earth and four seasons. In the documentaries China Enters a New Era, shots of blue lake water appeared many times (Figures 5-10). "Blue" mainly means eternity, harmony and calmness, while "water" means softness, purity, inclusiveness, integrity and so on. Blue lake water in the visual mode, with soothing music plays in the background, activates the semantic mapping of "blue lake water" under the conceptual domain. It is a metaphor that China is a country rising peacefully with the character of a gentleman. It will always enrich everything without seeking fame or wealth.
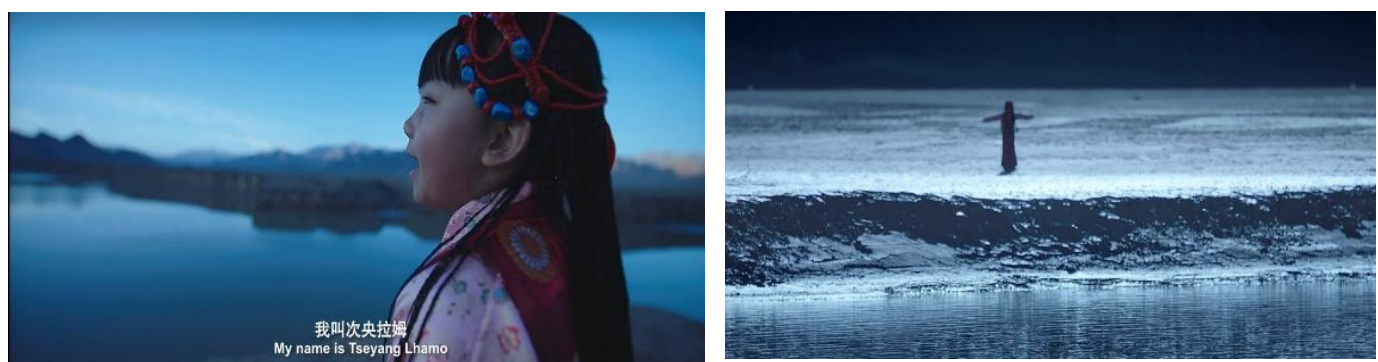

Figure 9-10 Lake Water in China Enters a New Era

\subsection{Personification Metaphor}

A NATION IS A PERSON is one of the central metaphors in the NIPD China Enters a New Era. Through personification, China is portrayed as a person who is growing and developing. China is a brave and confident person. China opened the door to the outside world 40 years ago. China has preserved its own special character in its meeting with the world, bravely facing new opportunities and challenges, actively integrating into the development trend of this time, and confidently choosing the path of socialism with Chinese characteristics shown in the verbal mode "Thirty years of opening has 
been a time of bravely facing the new and stepping forward on a path of our own choosing."

THE WORLD IS A PERSON is another central conceptual metaphor in the NIPD Enters a New Era. In the documentary, the world is regarded as a person who makes judgments about China and witnesses the development of China shown in the verbal mode. Since the reform and opening up, panorama of changes has taken place in China, which dazzled the world which can be seen from the verbal mode that "China suddenly dazzled people with the panorama of change." China's economic development provides the driving force for the development of world economy, and China's political democracy is applauded by the world.

\section{Conclusion}

National image is the representative of country's soft power, and also is the one of the manifestations of a country's comprehensive strength. Based on the theoretical framework of conceptual metaphor theory proposed by Lakoff \& Johnson, this study attempts to figure out (a) the types of metaphor in National Image Publicity Documentary China enters a new era, (b) meaning construction of multimodal metaphors, and (c) what kinds of national image have been constructed by multimodal metaphor. The major findings are as follows: Firstly, the main types of multimodal metaphor are JOURNEY METAPHOR, EMOTIONAL METAPHOR, PERSONIFICATION METAPHOR; Secondly, focusing on the main dimensions of the construction of national image, the documentary China enters a new era present following national images: developmental, objective and true holistic image of the nation, open city image, and civilized national quality.

\section{Acknowledgements}

This paper is supported by the research project [20XJKT069] in Zhejiang University of Finance and Economics. A Study on Validity and Washback of Integrated Writing: Continuation Task of the New National Matriculation English Test (NMET).

\section{References}

[1] El Refaie, E. (2003) Understanding visual metaphor: The example of newspaper cartoons. Visual Communication volume1: 75-96.

[2] Forceville, C. (1996) Pictorial Metaphor in Advertising. London/ New York: Routledge.

[3] Forceville, C. (2009) The role of non-verbal sound and music in multimodal metaphor. In Forceville, C. \& Urios-Aparisi, E. (eds.). Multimodal Metaphor. Berlin: Mouton de Gruyter, 383-400.

[4] Hou, R. \& Zhao, X. (2010). The Composition and Interpretation of Multimodal Metaphor in Advertisements. Educational Research on Foreign Language and Arts, (1): 6-9.

[5] Jiang, G. \& Wang, R. (2013) A Study on the Fusion of Verbal-gestural Multimodal Metaphors in English Speeches. Foreign Language Research, (5): 9-16.

[6] Koller, V. (2009) Brand images: Multimodal metaphor in corporate branding messages. In Forceville, C. J. \& Urios-Aparisi, E. (Eds), Multimodal Metaphor. York: Mouton de Gruyter, 45-71.

[7] Lakoff, G. \& Johnson, M. (1980) Metaphors We Live by. Chicago: University of Chicago Press.

[8] Lakoff, G. (1980) The contemporary theory of metaphor. A. Ortony, 202-51.

[9] Ning, Y. (2009) Nonverbal and multimodal manifestation of metaphors and metonymies: a case study. In Forceville, C. \& Urios-Aparisi, E. (Eds.). Multimodal Metaphor. Berlin: Mouton de Gruyter, 119-143.

[10] Pan, Y. \& Zhang, H. (2013) The Cognitive Mechanism of Multimodal Discourse: A Case Study of the 
Documentary China's National Image Promotion: Perspectives. Foreign Language Research, (1):10-19.

[11] Rohdin, M. (2009) Multimodal metaphor in classical film theory from the 1920s to the 1950s. In Forceville, C. J. \& Urios-Aparisi, E. (Eds), Multimodal Metaphor. Berlin: Mouton de Gruyter, 403-428.

[12] Sperandio, N. E. (2020) The role of multimodal metaphors in the creation of the fake news category: a proposal for analysis. Rev. Estud. Ling., Belo Horizonte, (2): 777-799.

[13] Yu, N. (2009) Nonverbal and multimodal manifestation of metaphors and metonymies: A case study. In Forceville, C. J. \& Urios-Aparisi, E. (Eds), Multimodal Metaphor. York: Mouton de Gruyter, 119-143.

[14] Wang, H. \& Xin, B. (2019) A Study on the Metaphorical Construction of China's Image in the US Media: A Case Study of “The United States Withdraws from TPP”. Foreign Language Education, (3):32-38.

[15] Zhao, X. (2013) The Conceptual Integration Model of Multimodal Metaphor Construction: A Case Study of a Political Cartoon. Foreign Language Research, (5):1-8. 